\title{
Resistiendo la acumulación por desposesión en los manglares ecuatorianos: los Pueblos Ancestrales del Ecosistema Manglar y su política de producción de comunes
}

Résister à l'accumulation par la dépossession dans les mangroves de l'Équateur: les peuples ancestraux de l'écosystème de la mangrove et leur politique de production de biens communs

Resisting accumulation by dispossession in Ecuador's mangroves: the Ancestral Peoples of the Mangrove Ecosystem and their commons production policy

\section{Sara Latorre}

\section{(2) OpenEdition}

1 Journals

Edición electrónica

URL: https://journals.openedition.org/bifea/12494

DOI: $10.4000 /$ bifea. 12494

ISSN: 2076-5827

Editor

Institut Français d'Études Andines

\section{Edición impresa}

Fecha de publicación: 8 diciembre 2020

Paginación: 321-340

ISSN: 0303-7495

\section{Referencia electrónica}

Sara Latorre, «Resistiendo la acumulación por desposesión en los manglares ecuatorianos: los Pueblos Ancestrales del Ecosistema Manglar y su política de producción de comunes», Bulletin de I'Institut français d'études andines [En línea], 49 (2) | 2020, Publicado el 25 noviembre 2021, consultado el 01 diciembre 2021. URL: http://journals.openedition.org/bifea/12494 ; DOI: https://doi.org/10.4000/ bifea.12494

\section{(c)}

Les contenus du Bulletin de l'Institut français d'études andines sont mis à disposition selon les termes de la licence Creative Commons Attribution - Pas d'Utilisation Commerciale - Pas de Modification 4.0 International. 


\title{
Resistiendo la acumulación por desposesión en los manglares ecuatorianos: los Pueblos Ancestrales del Ecosistema Manglar y su política de producción de comunes
}

\author{
Sara Latorre*
}

\begin{abstract}
Resumen
Este artículo analiza el proceso de encerramiento del ecosistema manglar en la costa ecuatoriana por parte de la industria piscícola del camarón y las acciones colectivas implementadas por el movimiento en defensa del ecosistema manglar. Con el objetivo principal de garantizar las formas de vida de la población recolectora, dicho movimiento social implementó una novedosa estrategia política étnica mediante la cual se posicionaron como «Los Pueblos Ancestrales del Ecosistema Manglar (PAEM)» y reivindicaron su derecho colectivo al territorio-manglar. A través de esta estrategia étnica, dicho movimiento social buscó, aunque sin éxito, la posibilidad de producir «comunes» en oposición a los espacios privatizados de las camaroneras, por ejemplo, espacios de vida alternativos donde recrear «una nueva comunidad de pertenencia» emancipadora.
\end{abstract}

Palabras clave: acumulación por desposesión, estrategia política identitaria, ecosistema manglar, Ecuador, industria piscícola del camarón

Résister à l'accumulation par la dépossession dans les mangroves de l'Équateur: les peuples ancestraux de l'écosystème de la mangrove et leur politique de production de biens communs

\section{Résumé}

Cet article analyse le processus de confinement de l'écosystème de mangrove sur la côte équatorienne par l'industrie de la crevette et les actions collectives mises en œuvre par le mouvement de défense de l'écosystème de mangrove. Afin de garantir essentiellement les formes de vie de la population des

* Profesora-investigadora. Facultad Latinoamericana de Ciencias Sociales (FLACSO), Ecuador. E-mail: sara.latorre.tomas@gmail.com 
récolteurs, ledit mouvement social a mis en œuvre une nouvelle stratégie politique ethnique qui les positionne comme « les peuples ancestraux de l'écosystème de la mangrove-PAEM » et revendique leur droit collectif sur le territoire des mangroves. Au travers de cette stratégie ethnique, ce mouvement social a cherché, bien que sans succès, la possibilité de produire des « biens communs » en opposition aux espaces privatisés des élevages de crevettes, c'est-à-dire des espaces de vie alternatifs où recréer « une nouvelle communauté d'appartenance émancipatrice ».

Mots-clés : accumulation par dépossession, stratégie d'identité politique, écosystème de mangrove, Équateur, industrie de la crevette

\title{
Resisting accumulation by dispossession in Ecuador's mangroves: the Ancestral Peoples of the Mangrove Ecosystem and their commons production policy
}

\begin{abstract}
This article analyzes the enclosure process of mangrove ecosystem in the Ecuadorian coast by the shrimp farming industry, and the interrelated collective actions of resistance implemented by the social movement for the defense of mangroves. With the aim of increasing the power over the means mangrove gatherers' use to secure their livelihoods, this social movement implemented a novel ethnic political strategy by which it self-positioned as Ancestral Peoples of the Mangrove Ecosystems-PAEM and claimed the right to territory-mangroves. Through this ethnic politics strategy, it is argued, that this social movement sought, but without success, to produce "commons" in direct opposition to the privatized spaces of the shrimp farms.
\end{abstract}

Keywords: accumulation by dispossession, identity politics, mangrove ecosystem, Equator, shrimp farming industry

\section{INTRODUCCIÓN}

Este artículo analiza el proceso de encerramiento del ecosistema manglar en la costa ecuatoriana por parte de la industria piscícola del camarón y las acciones colectivas implementadas por el movimiento en defensa del ecosistema manglar.

El inicio de la industria piscícola en el Ecuador se produce en la provincia sureña de El Oro a finales de la década de los sesenta, llegando a su máximo crecimiento y expansión en las subsiguientes décadas (periodo de 1970-1990). Durante este auge camaronero, grandes extensiones de manglares fueron removidas para la instalación de piscinas camaroneras a lo largo de toda la costa ecuatoriana. El ecosistema manglar en el Ecuador se ubica en la zona intramareal cuyo propietario formal es el Estado ecuatoriano. Sin embargo, numerosas evidencias muestran que las zonas de manglar han sido habitadas y sus recursos naturales aprovechados desde el periodo precolombino, principalmente por poblaciones de recolectores de conchas y cangrejos y pescadores artesanales (Marcos, 2005). 
Por tanto, el uso y acceso de los manglares en el Ecuador, a pesar de ser estas áreas formalmente propiedad del Estado, ha venido históricamente gestionándose a través de un conjunto de instituciones no formales creadas por la población cuya forma de subsistencia ha estado tradicionalmente vinculada a este ecosistema. Esta gestión comunal de los manglares fue totalmente desconocida y desarticulada por parte del Estado ecuatoriano, quien activamente promovió el desarrollo de la industria piscícola camaronera. Como consecuencia de este proceso, la población recolectora vinculada al ecosistema manglar inició un proceso de organización y resistencia, y se consolidó en 1998 un movimiento social a nivel de toda la costa ecuatoriana bajo el liderazgo de la organización C-CONDEM (Coordinadora Nacional para la Defensa del Ecosistema Manglar). En el año 2007, dicho movimiento social implementó una novedosa estrategia política étnica, objeto de análisis del presente artículo. Se argumenta que dicha estrategia política identitaria buscó, aunque sin éxito, la posibilidad de reconstituir «comunes», en oposición a los espacios privatizados y mercantilizados de las camaroneras. Es decir, su finalidad fue crear espacios de vida alternativos desconectados de la lógica del mercado, donde pudieran «reinventar» una nueva comunidad étnica emancipadora: los Pueblos Ancestrales del Ecosistema Manglar-PAEM. Siguiendo a De Angelis (2004), no hay comunes sin comunidad a través de la cual las modalidades de acceso a recursos comunes son negociadas.

Este caso de estudio ilustra una de las muchas y diversas luchas contemporáneas de movimientos sociales que enfrentan las múltiples formas de encerramientos capitalistas o procesos de «acumulación por desposesión» que están teniendo lugar actualmente. Siguiendo la línea de varios autores como Harvey (2005) y De Angelis (2004) que siguen el planteamiento de Rosa Luxemburgo, entendemos que los procesos de acumulación originaria o de acumulación por desposesión son un elemento constitutivo de las relaciones capitalistas y de acumulación. El capital necesita de las estrategias de acumulación originaria para recrear las bases de acumulación, y para esto precisa dónde llevar a cabo tal acumulación como los manglares. Este proceso geográfico de reorganización se produce a través de la producción de un desarrollo desigual —-temporal y espacialmente-, en que la desposesión (y no la generación neta de capital) es una condición necesaria para la acumulación de capital. Estas condiciones desiguales tienden a causar profundas alteraciones en las formas de vida y relaciones sociales de varios grupos marginalizados (la tragedia de los comuneros), que a su vez pueden iniciar acciones de resistencia y procesos de organización política, como es el caso de este movimiento social en defensa del ecosistema manglar.

Una de las modalidades de acumulación por desposesión que describen estos autores y que ilustra perfectamente este caso de estudio es la conversión de varias formas de propiedad (comunal, estatal, libre acceso) en derechos de propiedad privada. Este es un tópico de suma relevancia debido a la gran expansión de procesos de acumulación por apropiación que se están dando a escala global actualmente, especialmente en el sur global donde predominan los países ricos en recursos naturales, con bajo PIB e ingresos, como el Ecuador (Latorre et al., 2015). 
El material para este artículo se deriva de la tesis doctoral de la autora (Latorre, 2013). En el marco de esa investigación, se realizó trabajo de campo durante el periodo 2009-2012 con una duración total de once meses. Se realizaron 32 entrevistas semiestructuradas a los principales líderes de la ejecutiva del movimiento (C-CONDEM), así como a los principales líderes de las organizaciones base del mismo y que participaron en el primer congreso sobre PAEM (siete entrevistas). En estas se buscó indagar sobre el proceso de formación del movimiento, su posicionamiento como PAEM, así como su posición ante la regularización de la industria piscícola camaronera. Asimismo, se realizaron diez entrevistas a informantes clave tanto del Estado con competencia sobre los manglares e industria camaronera como a representantes de la industria del camarón y ONG ambientalistas. Se asistió a cinco encuentros celebrados por el movimiento de defensa del manglar, y se realizó observación participante durante seis meses en diferentes zonas del manglar de la costa ecuatoriana. Toda este material primario se complementó con información secundaria relacionada con la producción escrita creada por este movimiento social. Finalmente, la sistematización y codificación de la misma se realizó a través del software Nvivo.

El artículo procede de la siguiente manera: en la siguiente sección, se presenta el proceso de encerramiento de los manglares, destacando las políticas y actores que lo hicieron posible. A continuación, se analiza la estrategia política identitaria del movimiento en defensa del manglar, haciendo énfasis en los criterios de exclusión e inclusión de su novedosa autodenominación étnica y su política en pos de reconstituir comunes. Finalmente, se concluye con una reflexión sobre la emergencia de nuevas indigeneidades en contextos de desposesión ambiental.

\section{EL PROCESO DE ENCERRAMIENTO DE LOS MANGLARES ECUATORIANOS}

El proceso de encerramiento de los manglares en el Ecuador, es decir, el conjunto de políticas y prácticas a través de las cuales se promovió y profundizó la separación de los recolectores del manglar de sus medios de producción y vida, se puede dividir en cinco grandes fases que se describen a continuación.

\section{1. Fase I (hasta 1984). Los manglares: de espacios multifuncionales desvalorizados por el capital a espacios de monocultivos dominados por un grupo poderoso y unificado de actores}

Las poblaciones recolectoras del manglar, a nivel de toda la costa ecuatoriana, viven en condiciones de vulnerabilidad social y pobreza, con patrones de trabajo informal y relaciones de explotación por parte de los intermediarios. Por el contrario, existen diferencias entre ellas, sobre todo con relación a sus patrones de asentamiento (islas cerca de los manglares, continente en zonas urbanas, continente cerca de manglares), su longevidad o no realizando estas actividades 
económicas, sus autopercepciones raciales/étnicas y su proceso de organización social. A pesar de esta heterogeneidad, las identidades productivas, como ser cangrejeros o concheros, combinado con condiciones socioeconómicas similares, tienen un rol muy importante en sus procesos de autoidentificación diarios (notas de campo, diciembre de 2010).

La zona intramareal donde se ubican los manglares es considerada patrimonio nacional, donde la posesión privada de tierra está prohibida formalmente y su uso y gestión es responsabilidad del gobierno. Este puede conceder a terceros su aprovechamiento a través del mecanismo de concesiones, como aplicó con la industria acuícola del camarón. Sin embargo, hasta finales de los sesenta, los manglares eran vistos como espacios improductivos sin potencial para contribuir al desarrollo económico del país (ECOBIOTEC, 2009). Por este motivo, hasta el inicio de la acuicultura camaronera, este ecosistema actuó como un espacio de vida relativamente descolonizado por relaciones capitalistas de producción. En él predominaron actividades productivas de subsistencia, como la producción de carbón, el uso de madera para viviendas, la pesca artesanal y la recolección de cangrejos y moluscos.

Esta situación cambió con el inicio de la industria acuícola camaronera. Es importante mencionar que el sector camaronero ecuatoriano es un actor muy poderoso dominado por una clase económica media y alta con relaciones cercanas a personalidades clave del Estado ecuatoriano (Olsen \& Coello, 1995; Gary, 2000). A través del mecanismo de concesiones, con una duración de diez años y con costos muy bajos (US\$10/ha), el gobierno ecuatoriano impulsó el desarrollo de dicha industria. Entre 1979 y 1986, fue el periodo de su mayor expansión debido a varios factores, como los altos precios internacionales del camarón y la abundancia de «post-larvas» salvajes de camarón que eran el insumo necesario para las piscinas. De este modo, de cero piscinas camaroneras en 1969, se pasó a 89368 hectáreas de piscinas en 1984 (Centro de Levantamientos Integrados de Recursos Naturales por Sensores Remotos-CLIRSEN, 1990). Y de estas, el 70 \% fueron construidas en zonas de manglar (LiPUMA \& Meltzoff, 1985 en Sutinen et al., 1989).

Debido a esta fuerte deforestación del manglar, en 1978 el gobierno ecuatoriano promulgó el Decreto Supremo n. ${ }^{\circ} 239$ que prohibía la transformación del manglar en piscinas camaroneras (Gobierno del Ecuador, 1978). Por tanto, desde ese año, la expansión de la industria en zonas de manglar se realizó de forma ilegal, lo que denota el poder y la impunidad de este sector. Según Robadue Jr. (1995), el 9 \% de las piscinas camaroneras eran ilegales en 1984 y la pérdida promedio de manglar entre 1969 y 1984 fue de 1439 hectáreas (Olsen et al., 1995). Es importante resaltar que además de la adquisición de las áreas donde se ubicarían las piscinas camaroneras, sus dueños se apropiaron de las zonas aledañas, prohibiendo el paso de los recolectores de manglar. Las acciones de resistencia de este último grupo, con poco poder y organización social, fueron muy pocas para este periodo.

En resumen, durante esta fase, el Estado ecuatoriano hizo uso legal de su autoridad sobre los manglares para concesionarlos a quienes tuvieran los medios económicos 
para desarrollar grandes proyectos de acuacultura. Con ello, desconoció las prácticas y usos tradicionales (manejo comunitario de facto) que los recolectores del manglar venían realizando por siglos. Por el contrario, contribuyó a solidificar un nuevo régimen de propiedad en que las áreas multiusos de manglar se convirtieron en monocultivos dominados por un grupo poderoso y unificado de actores, como el sector camaronero.

\section{2. Fase II (1985-1989). La conservación virtual del manglar y la amenaza de los recolectores}

Como respuesta a las tasas alarmantes de deforestación del manglar, el gobierno adoptó permisos de operación y concesión de piscinas camaroneras más estrictos, así como varios decretos que declaraban la conservación y restauración del manglar de interés general (Pérez \& Robadue Jr., 1989). Asimismo, se prohibieron las prácticas tradicionales de los recolectores del manglar. En términos generales, durante 1985-1989 el gobierno adoptó una política de conservación del manglar centralizada, a base de leyes y regulaciones que prohibían la instalación de más piscinas camaroneras y la tala del manglar, pero con pocos recursos económicos para su cumplimiento. Esta valoración del ecosistema manglar, al menos de forma retórica, responde en parte al reconocimiento internacional que en esa época se le empieza a dar al manglar por los múltiples servicios ambientales que provee (Matthews, 1993). Como resultado de estas políticas fallidas, las tasas de deforestación del manglar siguieron aumentando. La tasa promedio de deforestación fue 2434 hectáreas por año durante el periodo 1984-1987 y de 3348 ha/año para el periodo 1987-1991 (Bodero Q. \& Robadue Jr., 1995).

La falta de sustentabilidad de estas transformaciones costeras contribuyó a la implementación del Programa de Manejo de Recursos Costeros (PMRC) firmado en 1986 entre los gobiernos de Ecuador y Estados Unidos. Inicialmente fue concebido como un proyecto piloto de tres años, pero finalmente fue extendido hasta 2008. Entre 1986 y 1989, el PMRC se dedicó a explorar alternativas viables a la fallida política que prohibía la tala del manglar. Para ello, se trató de trabajar, sin éxito, con el sector camaronero y el gobierno para adoptar políticas más sustentables (suministro de post-larva y manejo del agua) en la industria (Olsen \& Coello, 1995). En general, el sector camaronero mostró poco interés por el bienestar de los recolectores del manglar y por garantizar la preservación de sus formas de vida.

En los años siguientes, el PMRC cambió de estrategia y empezó a trabajar con las autoridades locales y la población recolectora y pescadora que ya empezaba a sentir el impacto de la pérdida de productividad y acceso a los recursos costeros del manglar. Por tanto, su voluntad para participar en procesos de gestión marinocostera era alta. 


\section{3. Fase III (1989-1998). El reconocimiento de los recolectores de manglar en el manejo costero sustentable: las zonas de manejo especial}

En 1989, el gobierno ecuatoriano adoptó como programa oficial (Decreto Ejecutivo 375) la nueva propuesta de manejo costero realizada por el PMRC (Gobierno del Ecuador, 1989). Esta buscó hacer una transición desde el fallido manejo centralizado hacia otro más participativo y local basado en la creación de seis áreas piloto a lo largo de la costa (zonas especiales de manejo-ZEM) (Ochoa, 1995).

En cada ZEM, se creó un comité zonal como espacio principal de toma de decisiones. Los comités zonales estaban conformados por varias autoridades locales y grupos organizados de usuarios. Cada organización participante debía estar legalmente constituida, lo cual conllevó a la formación de cientos de organizaciones de usuarios del ecosistema manglar (Bodero Q. \& Robadue Jr., 1995). Este proceso organizativo permitió empoderar un poco más a los recolectores e involucrarlos en el manejo del manglar. También, actuó como base social para la posterior articulación del movimiento en defensa del ecosistema manglar.

Además del PMRC, dos curas vinculados a la teología de la liberación y que trabajan en la zona de Muisne, al sur de la provincia de Esmeraldas, fueron claves para el surgimiento de este movimiento social. Estos curas realizaron un trabajo intensivo con los recolectores del manglar y grupos de jóvenes preocupados por los impactos socioambientales causados por la industria camaronera. Como resultado de este proceso, en 1991 se forma un grupo de jóvenes católicos que en los años posteriores fundaría la organización de base FUNDECOL (entrevista personal, agosto de 2010). Esta estuvo conformada tanto por grupos de individuos con alta educación formal como por recolectores del manglar y militantes sindicales. Inicialmente sus acciones consistieron en vigilar las áreas de manglar y reportar a las autoridades las acciones ilegales. Posteriormente, sus objetivos se ampliaron hacia la conservación y el desarrollo comunitario. Su objetivo fue la conservación y restauración del manglar a través del fortalecimiento de la identificación de los recolectores con el manglar (Fajardo \& Torres, 2004). Para ello, utilizó una narrativa esencializada que enfatizaba la directa relación entre la identidad cultural y el ecosistema manglar conceptualizado como «territorio». El trabajo y narrativa de FUNDECOL facilitó la emergencia de un sentimiento de pertenencia, un «nosotros-los usuarios ancestrales del manglar» con una historia y subjetividad compartidas (Torres \& Yépez, 1999). Los dirigentes de esta organización de base impulsarán la articulación de las diversas organizaciones de base a lo largo de la costa y pasarán a formar parte de la directiva de C-CONDEM en 1998. Esta organización regional también adoptará este discurso esencializado sobre identidad cultural y territorio, como precedente de su novedosa estrategia étnica. Durante el periodo 1992-1994, el marco ecuatoriano de gestión costera fue reestructurado y descentralizado formalmente. En 1993, el PMRC elaboró una política nacional para el manglar en la que recomendaba, entre otras cosas, 
la adopción de planes de manejo específicos para cada zona de manglar y el involucramiento de los recolectores de manglar en su gestión (Robadue Jr., 1995). En 1995, como un paso adelante en esta dirección, se reconoció y permitió de nuevo las prácticas tradicionales de los recolectores de manglar (Decreto Ejecutivo 3327) (Gobierno del Ecuador, 1995). Sin embargo, este mismo decreto legalizaba las camaroneras ilegales construidas hasta 1994. Es importante señalar que en 1991 estas ocupaban 14037 hectáreas (10 \% del total) (Olsen \& Coello, 1995).

En 1994, a través de un decreto se declara una veda de tala de manglar de cinco años y se vuelve a reafirmar el interés público de su conservación. De este modo, a partir de 1995, la tasa de deforestación del manglar disminuye como se muestra en el cuadro 1.

Cuadro 1 - Evolución de las tipologías de uso del suelo (1984-1999)

\begin{tabular}{|l|c|c|c|c|c|}
\hline \multicolumn{7}{|c|}{ Tipologías de uso del suelo (ha) } \\
\hline & $\mathbf{1 9 8 4}$ & $\mathbf{1 9 8 7}$ & $\mathbf{1 9 9 1}$ & \multicolumn{1}{c|}{1995} & 1999 \\
\hline Manglares & 182157 & 175157 & 162187 & 146939 & 148483 \\
\hline $\begin{array}{l}\text { Piscinas } \\
\text { camaroneras }\end{array}$ & 89368 & 117729 & 145998 & 178072 & 175167 \\
\hline Salitrales & 20022 & 12274 & 6321 & 5109 & 4548 \\
\hline
\end{tabular}

Fuente: CLIRSEN (2007)

En esta fase, aunque se reconoce la multifuncionalidad de los manglares y se crean espacios participativos de toma de decisiones con la inclusión de las comunidades costeras, ninguna piscina camaronera ilegal fue revertida al Estado. Por el contrario, a través de varias resoluciones legales, estas fueron regularizadas. Ya para este periodo, además de la destrucción del manglar, la producción camaronera había causado la contaminación del agua y suelo y la reducción de las poblaciones de peces, moluscos y crustáceos asociados a este ecosistema. Como consecuencia, los recolectores de manglar, para quienes su subsistencia depende de este ecosistema, vieron cómo su calidad de vida iba deteriorándose de forma severa con el paso de los años.

\section{4. Fase IV (1999-2003). El limitado reconocimiento de las custodias de manglar}

El año 1999 se puede considerar un año de inflexión en la gobernanza costera ecuatoriana. El evento más destacado fue el Decreto Ejecutivo 11022 que otorgaba a los recolectores del manglar la posibilidad de acceder a concesiones de manglar (bajo un régimen de gestión comunal), más conocidas como custodias (Gobierno del Ecuador, 1999). Además, prologaba la prohibición de tala de 
manglar promulgaba en 1994. Es importante resaltar que este decreto usaba el término «usuarios ancestrales del ecosistema manglar» para hacer referencia a los recolectores y para acceder a estas concesiones comunitarias de manglar. Sin embargo, este no proporcionaba una definición del concepto. En la práctica, las primeras concesiones que se otorgaron fueron a grupos de recolectores organizados en asociaciones cuyos asentamientos humanos estaban cerca de los manglares, dado que se asumía que eran los que mejor los podían vigilar (comunicación personal, octubre de 2011). A pesar de una falta de definición clara del término, a través de este decreto, el Estado ecuatoriano, por primera vez, reconoce formalmente la existencia de poblaciones con una larga residencia en los manglares, lo que servirá posteriormente a la C-CONDEM para legitimar su estrategia étnica.

Varios factores contribuyeron a la promulgación de este decreto. En primer lugar, a nivel internacional durante la $7^{\circ}$ Conferencia de las Partes de la Convención RAMSAR (1999) se exhorta a que se establezca una moratoria a la industria acuícola camaronera. Segundo, a nivel nacional, la industria camaronera quedó totalmente devastada por el virus de la mancha blanca después de alcanzar en 1998 su máximo nivel de producción (Marriot García, 2003). Este virus agravó la ya delicada situación de la costa ecuatoriana que en 1997-1998 sufrió un evento climático de El Niño bastante devastador. Finalmente, durante los años 1998 y 1999, la ONG Greenpeace apareció en las costas ecuatorianas con su barco insignia Rainbow Warrior en el marco de su campaña internacional en defensa de los manglares y de sus poblaciones. Estas dos acciones tuvieron una fuerte visibilidad pública y sirvieron para ejercer presión sobre el gobierno ecuatoriano. La primera llegada de Greenpeace a Ecuador catapultó la consolidación de un movimiento en defensa del ecosistema manglar a nivel regional al formarse la C-CONDEM, bajo el liderazgo de FUNDECOL como se ha mencionado previamente. Desde su formación, la C-CONDEM trató de adaptar su organización interna a la realidad socioorganizativa de los recolectores, quienes, muchos de ellos, mantuvieron otras afiliaciones, como la vinculación al sector pesquero artesanal (El Oro) o al movimiento afroecuatoriano (norte de Esmeraldas). Lo que sí hizo fue ubicar un dirigente por provincia, quien trabajó en la consolidación de la organización y en la difusión del discurso iniciado por la FUNDECOL sobre derechos territoriales e identidad cultural.

En el año 2000 se instauraron formalmente los requisitos para la obtención de estas custodias de manglar, las cuales se establecieron por un periodo de diez años con la opción de renovación, además de garantizar a sus concesionarios el uso exclusivo de ellas. Su concesión a una organización de recolectores los obligaba a realizar actividades de vigilancia del manglar y a tener un plan de manejo para el área concesionada. Los costes de gestión del área debían ser asumidos por la propia organización concesionaria. Ante esta situación, algunas organizaciones se aliaron con ONG y universidades para poder cumplir con todos los requisitos y obtener la custodia. Durante el periodo 2000-2007, solo se otorgaron 26 custodias, que comprendían 19 514,99 hectáreas de manglares, debido a la dificultad de cumplir con los requisitos y exigencias (Coello et al., 2008). 
De acuerdo a varios interlocutores entrevistados, el mecanismo de custodias fue visto como un gran logro en el marco del reconocimiento de los derechos de acceso y uso de los manglares por parte de las poblaciones recolectoras y pescadoras. Además, lo veían como una herramienta poderosa para luchar contra la expansión camaronera. Sin embargo, entre las demandas iniciales del movimiento en defensa del manglar, estaba el control y administración de todas las áreas de manglar de forma integrada y comunal (y no solo el derecho formal a su uso). Asimismo, demandaban la revocación de las piscinas de camaroneras ilegales para poder ser reforestadas y entregadas a los recolectores (comunicación personal, setiembre de 2010). Para los recolectores, la no consecución de sus demandas conllevó a serias consecuencias, lo que se explica a continuación.

\section{5. Fase V (2003-presente). La auto-opresión de los recolectores y las custodias como nuevos encerramientos}

El mecanismo de custodia facilitó la estabilización de las áreas de manglar (CLIRSEN, 2007), pero no conllevó beneficios socioeconómicos significativos para sus custodios (Coello et al., 2008). En términos generales, las custodias de manglar llegaron en un momento en que ya quedaban pocas áreas de manglar en pie y muchas pesquerías habían colapsado debido a la declinante calidad del agua de los estuarios. Además, las custodias impulsaron el descontento social entre recolectores, ya que pocos accedieron a custodias en comparación con el número total de estas poblaciones (Beitl, 2012; ECOBIOTEC, 2009). En palabras de un dirigente de la C-CONDEM: el sistema de custodia «no significa el reconocimiento de nuestros derechos territoriales, en la práctica ha significado un tipo de privatización de las áreas de manglar que genera conflictos entre nuestras comunidades» (C-CONDEM, 2010: 9).

Esta situación revela cómo las custodias de manglar, en vez de ser un mecanismo adecuado para solventar los problemas de los recolectores de manglar, han servido para transformar los remanentes de este ecosistema en un nuevo tipo de encerramiento que genera conflictividad entre los recolectores por su posesión. Las custodias de manglar son propiedad de un grupo organizado de individuos, quienes, de forma muy similar a las concesiones camaroneras, se gestionan privadamente y se excluye a los individuos no pertenecientes al grupo. Por tanto, estas crearon un proceso de intradiferenciación entre los recolectores que amenazaba la solidaridad de clase entre este grupo social.

En síntesis, el proceso de encerramiento de los manglares ecuatorianos, un recurso natural común, se ha producido a través de varios procesos: a) la priorización y promoción de la industria acuícola del camarón por encima de otros sectores y actividades como las realizadas por los recolectores del manglar. Este proceso, conllevó el otorgamiento, a la industria del camarón, de varios recursos naturales comunes, como el agua limpia, las post-larvas y tierra pública, a expensas de los derechos consuetudinarios de los recolectores del manglar; b) la falta de 
cumplimiento del entramado legal que protegía el ecosistema manglar, y, por tanto, la falta de protección de los medios de producción de los recolectores de manglar; y c) el reconocimiento formal de los derechos de uso tradicionales de los recolectores de manglar que llegó ya cuando la salud ecológica de los manglares y de las pesquerías estaba en estado crítico, por lo que el régimen comunitario otorgado a los recolectores solo ha servido para profundizar aún más el proceso de auto-opresión de estas poblaciones socialmente vulnerables. Ante esta situación, el movimiento en defensa del ecosistema manglar, buscará trascender el derecho formal al uso de los manglares (bajo régimen comunitario), para buscar derechos políticos colectivos (derecho al territorio) que le podrían dar mayor poder sobre el ecosistema manglar (remanentes y camaroneras ilegales en zona de manglar) y revertir el proceso de encerramiento del manglar y de auto-opresión interno. En este proceso de autoidentificación étnica emergerá una nueva comunidad de pertenencia y solidaridad, como se argumenta a continuación.

\section{LOS PUEBLOS ANCESTRALES DEL ECOSISTEMA MANGLAR: UNA NUEVA COMUNIDAD DE PERTENENCIA EMANCIPADORA}

\section{1. El posicionamiento como PAEM: más allá de reivindicaciones de «sangre y tierra»}

Las condiciones de vida de los recolectores del manglar con el paso de los años se volvieron cada vez más precarias y las custodias de manglar, en vez de revertir esta situación, agravaron el problema de subsistencia de la mayoría de los recolectores del manglar (véase la figura 1). En este contexto, en 2007, representantes de varias organizaciones de base de la C-CONDEM celebraron el Primer Congreso de los Pueblos Ancestrales del Manglar en el cual se autoposicionaron como Pueblos Ancestrales y, basándose en ello, demandaron derechos colectivos:

Los pueblos y comunidades ancestrales del ecosistema manglar de la costa ecuatoriana, en el marco del Primer Congreso... decidimos: reafirmar nuestra condición de Pueblos Ancestrales a la luz de la Constitución Política del Estado Ecuatoriano y del Derecho Ancestral, con plenos derechos derivados de nuestra condición (Derechos Colectivos, incluidos los Territoriales); exhortamos la consideración inmediata en todas las Políticas Públicas de la necesidad del pleno reconocimiento de Nuestros Derechos Territoriales como Garantía Fundamental e Ineludible para Nuestra Continuidad y Trascendencia como Pueblos Ancestrales. La destrucción del ecosistema manglar es la principal amenaza contra Nuestros Derechos y Nuestro Territorio, exigimos medidas para parar la actividad industrial de Acuacultura de camarón (C-CONDEM, 2007).

Como muestra su declaración, este movimiento social articuló un discurso sobre derechos territoriales e identidad indígena basado en el concepto de «ancestralidad» y «pueblos». Específicamente, la política de la identidad implementada por 


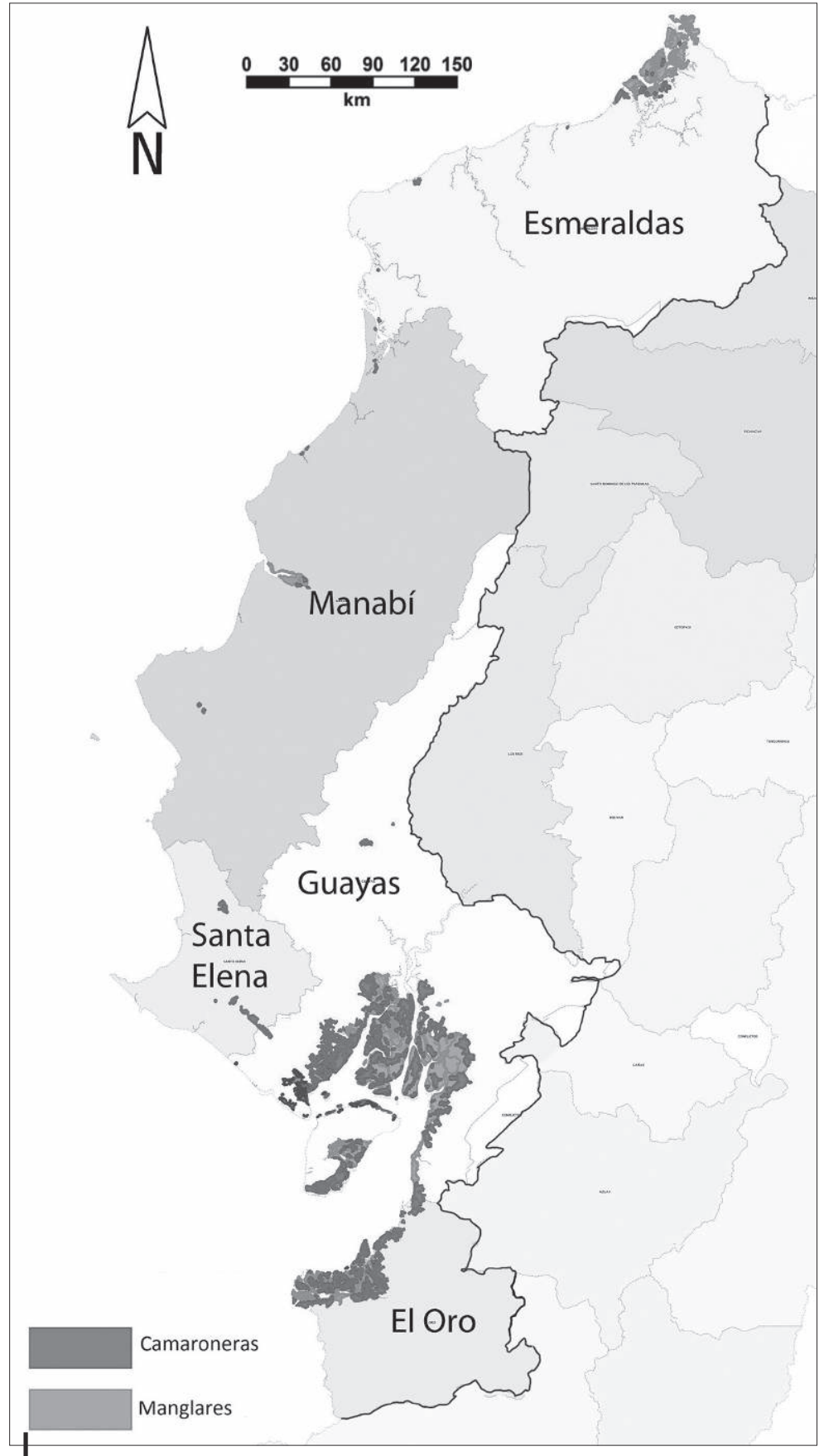

Figura 1 - Áreas de manglar y de camaroneras a lo largo de la costa ecuatoriana en 2007

Elaboración propia con la base de datos de SIG del Instituto Geográfico Militar, 2008 
la C-CONDEM enfatizó un sentido de pertenencia en conexión a la idea de ancestralidad en un ecosistema natural (los manglares).

Esta estrategia étnica debe ser entendida en el contexto de las décadas precedentes cuando el movimiento indígena ecuatoriano (MIE) adquiere gran relevancia en el campo político. Desde la década de los noventa, el MIE ha venido autorrepresentándose como «nacionalidades» y «pueblos» y exigiendo derechos colectivos basados en su diferencia cultural vis-a-vis de la sociedad «blancomestiza». Estas reivindicaciones fueron reconocidas, por primera vez, en la constitución ecuatoriana de 1998 (Gobierno del Ecuador, 2008). Desde entonces, en Ecuador, el discurso de la indigeneidad se ha vuelto un recurso político muy poderoso para negociar con el Estado derechos colectivos a la tierra. Diversos grupos sociales se están autoposicionando como indígenas en el marco de sus luchas por uso y acceso a recursos naturales, sobre todo, tierra (Bauer, 2010; Bazurco Osorio, 2006; González Andricaín, 2009).

Es importante resaltar que el término «pueblos indígenas» no tiene un conjunto de referentes fijos y naturales, sino que más bien es una categoría sociopolítica con derechos colectivos asociados. Además, esta se ha convertido en un término legal aplicado en contextos nacionales e internacionales para hablar de una identidad (una comunidad de pertenencia) reclamada por diferentes grupos sociales con trayectorias de vida muy diversas. En muchos casos, el término «pueblos indígenas» hace referencia a todos aquellos grupos sociales que comparten la misma expectativa de que legislaciones nacionales e internacionales reconozcan sus reclamos con relación a desposesiones vividas, sobre todo, derechos de uso de tierra y recursos naturales (Niezen, 2003). A pesar de que el movimiento transnacional sobre los derechos indígenas ha rechazado dar una definición cerrada sobre el término «indígena», y que más bien aboga para que sean los propios grupos que se autoidentifiquen, existe un conjunto de ideas núcleo que actúan como el prototipo de pueblos indígenas a nivel internacional. Estas, además, actúan como modelo referencial para la legitimización de la «autenticidad» de los pueblos indígenas. Este modelo referencial internacional está basado en las categorías coloniales de «nativos» americanos y «aborígenes» australianos. Sin embargo, a medida que el concepto se ha difundido en otros contextos, su significado se ha transformado para adaptarse a esas realidades, aunque se ha mantenido la idea de «otro originario» (Bowen, 2000). Por tanto, las identidades etnorraciales se entienden como cambiantes, descentralizadas, relacionales, sujetas a movilización política, entrelazadas con otras posiciones de sujeto como la clase o género, y que generan (aunque momentáneamente) comunidades de pertenencia y solidaridad para quienes se adscriben a estas (Hamilton \& Placas, 2011; Clifford, 2001; Bowen, 2000; Wade, 2010 [1997]). Estos factores enfatizan la fluidez de los significados etnorraciales, así como su carácter político (Hoffman French, 2004; Li, 2010; Hooker, 2005).

En América Latina, este concepto está directamente asociado a la categoría racial de «Indio» y asume una diferencia cultural racializada. Además, este modelo indígena (léase Indio) actúa como el modelo convencional de sujeto étnico. Lo que 
implica, en la práctica, que aquellos grupos sociales que reivindiquen su etnicidad deben hacerlo de manera que parezcan «indios» (Anderson, 2007; Wade, 2010 [1997]), reforzándose de este modo, la hegemonía de un sujeto étnico basado en la premisa subyacente de que todas las identificaciones étnicas deben enmarcarse en categorías racialmente homogéneas.

Por esta razón, la imagen pública posicionada por la ejecutiva de la C-CONDEM buscó estratégicamente encajar con el modelo representacional dominante vinculado con la categoría de «pueblos indígenas» que en Ecuador es el posicionado por el MIE. Con ello, buscaban aumentar sus posibilidades de ser reconocidos por el Estado. Esto explica por qué su régimen de representación, al igual que el del MIE, enmarca su demanda sobre la tierra (las áreas de manglar) en un discurso en que la territorialidad es vista como soporte para el mantenimiento de una forma de vida cultural que es autorrepresentada como ambientalmente sostenible. En ambos, se naturaliza la relación entre identidad cultural y un ecosistema-lugar, es decir, se asume una cultura diferente basada en su larga residencia y adaptación al territorio (los manglares). Sin embargo, dado que la base social de la C-CONDEM estaba constituida por un grupo racialmente heterogéneo, esta organización tuvo que plantear una nueva identidad étnica-indígena (sin connotaciones raciales), una nueva comunidad de pertenencia que unificara y movilizara a este grupo social. Objetivo que logró con el término «Pueblos Ancestrales» que hace referencia a su condición de nativo y al mismo tiempo se distancia de connotaciones raciales. En este sentido, este movimiento social elaboró un contradiscurso que justifica su derecho a poseer los manglares como propiedad colectiva de una comunidad ancestral culturalmente diferente.

Su posicionamiento como PAEM a inicios de 2007 responde al contexto de oportunidades políticas de ese periodo: en noviembre de 2006, el candidato presidencial de Alianza País (AP), Rafael Correa, ganó las elecciones e inmediatamente convocó a una Asamblea Constituyente que empezó en noviembre de 2007. Entre los integrantes de AP, hubo algunas personalidades clave con una larga trayectoria de apoyo al movimiento ambiental ecuatoriano1. Asimismo, el plan de gobierno de AP contemplaba propuestas ambientales bien claras. Estos factores contribuyeron a que el movimiento en defensa del ecosistema manglar viera una oportunidad política favorable para su reconocimiento como pueblo étnico, y de este modo reducir su vulnerabilidad. Como el presidente de la C-CONDEM manifestó, «queríamos sentar un precedente para evitar que los camaroneros pudieran legalizarse. Ya hubo varios intentos en anteriores gobiernos» (28 de agosto de 2010).

1 Alberto Acosta fue el miembro más importante, quien a lo largo de su trayectoria apoyó al movimiento ecologista ecuatoriano. Otros miembros de AP, como Lucy Ruiz y José Serrano, también han mantenido estrechas relaciones con el movimiento ecologista. Por otro lado, en el plan de gobierno de AP, incita a buscar una nueva relación entre los humanos y la naturaleza basada en el principio de armonía, en la que la mercantilización de la naturaleza no tuviera cabida. Véase http://www.latinreporters.com/equateurRafaelCorreaPlandeGobiernoAlianzaPAIS.pdf. 
Esta nueva categoría política identitaria creó una comunidad de pertenencia mucho más amplia y emancipadora de lo que su régimen de representación indica (recolectores nativos de las áreas de manglar). De acuerdo a un miembro de la ejecutiva de la C-CONDEM:

Uno no es un miembro de los pueblos ancestrales porque nació allí (en los manglares); al contrario, es quien practica los usos y costumbres que ancestralmente se han venido realizando, es decir, respectar la naturaleza, recolectar las buenas conchas, respetar las épocas de veda... todo esto ha venido realizando nuestra gente sin necesidad de leyes, pero por supuesto, hay una necesidad de regular (el uso del manglar) porque, como tú dices, nuevos recolectores están llegando y no conocen... nosotros les decimos: "mira, el bueno tamaño es este, la recolección se hace de esta manera, ahora estamos en veda... mira en el día de San Antonio nadie va a recolectar y se queda bailando" (miembro de la ejecutiva C-CONDEM, noviembre de 2010).

Para citar a otro líder, nacido en una comunidad cercana a los manglares en la provincia de Esmeraldas:

Yo considero que la categoría de PAEM incluye a aquellos que están ahí (en los manglares) y a los nuevos que se van asentando porque se han vuelto parte de nosotros, esa es la verdad. Sin tomar en cuenta que han llegado recientemente, ellos migraron, llegaron para buscar trabajo y nadie tiene el derecho a expulsarlos, nadie puede decir váyanse porque están buscándose una mejor vida, pero ellos se deben de integrar y respetar las reglas (miembro de la C-CONDEM, diciembre de 2011).

La inclusividad del término PAEM, la cual abarca a los nuevos recolectores, también es expresada por otro miembro de la provincia del Guayas, quien es además nativo de una comunidad isleña cercana a los manglares:

En relación a los recolectores inmigrantes, son gente que vino de la ciudad a vivir en comunidad, dejando su confort y el resto de cosas. Lo hacen para vivir de los manglares, nadie de la ciudad vendría aquí para hacer otras cosas que no fuera recolectar concha, cangrejos... Yo no tendría ninguna objeción de incluirles porque ellos vienen para vivir de los manglares (miembro de la C-CONDEM, diciembre de 2011).

De acuerdo a otro miembro de la C-CONDEM quien, a diferencia de los dirigentes anteriores, no nació en la costa ecuatoriana, pero migró a la provincia de El Oro hace más de 50 años y empezó a recolectar cangrejos en los manglares:

Los PAEM hacen referencia primero que todo a aquellos que son nativos, pero yo me sentí parte de ellos por la lucha que realicé para defenderlos. Y todavía me siento parte de ellos porque yo empecé la lucha aquí con mi compadre y dos compañeros. Por esta razón, yo le digo a él (al presidente de la comunidad Bellavista), quien vendió la comunidad y los manglares a los camaroneros, y le dieron custodia de manglar solo porque era nativo, pero ser nativo no implica necesariamente que cuide los manglares, al contrario (miembro de la C-CONDEM, setiembre de 2010). 
De todos estos testimonios, se deriva que para ser parte de los PAEM no necesariamente o exclusivamente debes ser nativo. Elementos como la defensa de los manglares (contra los camaroneros) y la adopción de prácticas y usos ambientalmente sustentables juegan un rol mucho más determinante para ser incluido o excluido en esta categoría política. En este sentido, sugiero que la categoría de PAEM expresa una identidad relacional en directa oposición a la de los camaroneros; son dos formas de vida opuestas, con diferentes racionalidades económicas y niveles de vinculación y dependencia sobre el medioambiente. Aunque este movimiento social enfatizó públicamente los principios de «sangre y tierra» - típicamente asociados al discurso dominante sobre indigeneidadcomo mecanismo para aumentar las posibilidades de reconocerles sus derechos territoriales, esta categoría política es mucho más amplia y emancipadora. Incluye, además, a todos los recolectores, independientemente de ser nativos o no, que se organizaron y adoptaron prácticas tradicionales sustentables de uso del manglar. Sin embargo, este término excluye a los recolectores de manglar que eligen no organizarse y trabajar de forma independiente.

A pesar de dos congresos más sobre PAEM en los años siguientes, las demandas del movimiento en defensa del manglar no han tenido una respuesta positiva por parte del gobierno ecuatoriano. Esta comunidad política de pertenencia, además de tener que luchar contra un modelo étnico hegemónico monorracializado como se ha argumentado previamente, ha visto cómo el gobierno de AP, a partir de 2008, ha venido impulsando fuertemente la industria acuícola del camarón. Hasta el momento, se han legalizado 42000 hectáreas de camaroneras irregulares que eran las que el movimiento reclamaba que se revirtieran a áreas de manglar y se las otorgaran como parte de su territorio. Con ello, se ha cerrado la posibilidad de revertir la expansión ilegal de esta industria y restaurar el severo daño ambiental causado sobre los manglares. Como consecuencia, esta novedosa comunidad de pertenencia y solidaridad que comportó la disolución (aunque momentánea) de las diferencias raciales/étnicas intragrupales de sus miembros, se ha desarticulado. Desde 2009, el movimiento en defensa del ecosistema manglar se ha fragmentado, sus bases mestizas se han separado de este y el resto de sus organizaciones bases han venido luchando y adoptando ahora el discurso étnico hegemónico y racializado para seguir exigiendo el derecho al territorio-manglar (Latorre, 2013). Este hecho resalta la importancia de entender los contextos sociales y materiales que hacen posible indigeneidades étnicamente heterogéneas, como los PAEM.

\section{CONCLUSIONES}

Este artículo ha presentado un caso de estudio en que la estrategia política basada en la identidad y el lugar ha servido para articular un proyecto de reconstitución de comunes emancipador para luchar contra el proceso de marginalización de los recolectores de manglar como colectividad. En este sentido, la estrategia política basada en la identidad puede ser entendida como una lucha por el reconocimiento y como una condición necesaria para superar injusticias políticas 
y distributivas. Como señala Schlosberg (2004), la falta de reconocimiento está altamente relacionada con la destrucción de los ambientes locales y la exclusión de los grupos sociales de la esfera política.

El caso del movimiento en defensa del ecosistema del manglar ha mostrado cómo el poder y la identidad son negociados en contextos de desposesión ambiental. La política de la identidad puede servir para debatir y confrontar varias formas de propiedad y acceso a recursos naturales. En este caso, ha servido para cuestionar y resistir el proceso de encerramiento de los manglares y su gestión privada por parte de la industria camaronera.

Este caso de estudio es además emblemático de cómo los actuales procesos de desposesión ambiental están impulsando la emergencia de nuevas indigeneidades. Estos nuevos sujetos políticos están emergiendo en lugares que no han sido tradicionalmente asociados con una población indígena o donde se dice que la población indígena desapareció por procesos de asimilación. Por tanto, estas nuevas estrategias identitarias están emergiendo con fuertes tensiones. Dada la gran heterogeneidad de los grupos sociales ambientalmente desposeídos, en estos procesos de emergencia de nuevas indigeneidades, dichos grupos están resignificando las premisas fundacionales del término (una diferencia cultural racializada y habitantes originarios). En este sentido, PAEM ha empujado las fronteras políticas y epistemológicas de la indigeneidad de forma tal que invita a ver este concepto más allá de los principios de raza o «suelo y tierra». Este caso tiene similitudes, pero también diferencias, con otros casos de Latinoamérica, como Honduras o Brasil, donde grupos sociales con una clara apariencia física afrodescendiente están reivindicando su condición de indígenas (afroindigeneidad) (Anderson, 2007; Hoffman French, 2004). Finalmente, este caso de estudio invita, por un lado, a una reflexión crítica sobre las epistemologías indígenas hegemónicas que definen quién será o no incluido como indígena, y, por otro, a cuestionarse sobre la necesidad y legitimidad de reconocer derechos de subsistencia ecológica a grupos sociales contemporáneos que experimentan procesos de desposesión ambiental.

\section{Referencias citadas}

ANDERSON, M., 2007 - When Afro Becomes (like) Indigenous: Garifuna and AfroIndigenous Politics in Honduras. Journal of Latin American and Caribbean Anthropology, 12 (2): 384-413.

BAUER, D. E., 2010 - Re-articulating Identity: The Shifting Landscape of Indigenous Politics and Power on the Ecuadorian Coast. Bulletin of Latin American Research. Journal of the Society for Latin American Studies, 29 (2): 170-186. 
BAZURCO OSORIO, M., 2006 - "Yo Soy Más Indio Que Tú". Resignificando la etnicidad: exploración teórica e introducción al proceso de reconstrucción étnica en las comunas de la península de Santa Elena, 193 pp.; Quito: Ediciones Abya-Yala, Escuela Superior Politécnica del Litoral (ESPOL).

BEITL, C. M., 2012 - Shifting Policies, Access and the Tragedy of Enclosures in Ecuadorian Mangrove Fisheries: Towards a Political Ecology of the Commons. Journal of Political Ecology, 19: 94-113.

BODERO Q., A. \& ROBADUE Jr., D., 1995 - Strategies for Managing Mangrove Ecosystems in Ecuador. In: Eight Years in Ecuador: The Road to Integrated Coastal Management (D. Robadue Jr., ed.): 43-69; Narragansett: Coastal Resources Center, University of Rhode Island.

BOWEN, J. R., 2000 - Should We Have a Universal Concept of 'Indigenous Peoples' Rights'? Ethnicity and Essentialism in the Twenty-First Century. Anthropology Today, 16 (4): 12-16.

CENTRO DE LEVANTAMIENTOS INTEGRADOS DE RECURSOS NATURALES POR SENSORES REMOTOS (CLIRSEN), 1990 - Estudio multitemporal de los manglares, camaroneras y áreas salinas de la costa ecuatoriana, mediante información de sensores remotos, 91 pp.; Quito: CLIRSEN ed.

CENTRO DE LEVANTAMIENTOS INTEGRADOS DE RECURSOS NATURALES POR SENSORES REMOTOS (CLIRSEN), 2007 - Actualización del estudio multitemporal de manglares, camaroneras y áreas salinas en la costa continental ecuatoriana al año 2006. Resumen ejecutivo, 77 pp.; Quito: Presidencia de la República del Ecuador (PMRC), Ministerio del Ambiente.

CLIFFORD, J., 2001 - Indigenous Articulation. The Contemporary Pacific, 13 (2): 468-490.

COELLO, S., VINUEZA, D. \& ALEMAN, R., 2008 - Evaluación del desempeño de los acuerdos de uso sustentable y custodia de manglar de la zona costera del Ecuador, 52 рр.; Quito: Ministerio del Ambiente del Ecuador, Conservación Internacional, Unión Mundial para la Naturaleza (UICN), Comisión Mundial de Áreas Protegidas de UICN, Programa de apoyo a la gestión descentralizada de los recursos naturales en las tres provincias del norte del Ecuador (PRODERENA), Ecobiotec.

COORDINADORA NACIONAL PARA LA DEFENSA DEL ECOSISTEMA MANGLAR (C-CONDEM), 2007 - Declaración de los Pueblos Ancestrales del Ecosistema Manglar. I Congreso sobre sus derechos fundamentales. Sin publicar.

COORDINADORA NACIONAL PARA LA DEFENSA DEL ECOSISTEMA MANGLAR (C-CONDEM), 2010 - Pueblos Ancestrales del Ecosistema Manglar del Ecuador. Recuperando comunitariamente su territorio, 48 pp.; Quito.

DE ANGELIS, M., 2004 - Separating the Doing and the Deed: Capital and the Continuous Character of Enclosures. Historical Materialism, 12 (2): 57-87.

ECOBIOTEC, 2009 - Situación actual. Concesiones de manglar en la reserva ecológica Cayapas Mataje y el área de influencia de la reserva Manglares Churute y estado de conservación del manglar de la isla Mondragón. USAID Costas y Bosques Sostenibles, $34 \mathrm{pp}$.

FAJARDO, M. \& TORRES, M., 2004 - Experiencia de la Fundación de Defensa Ecológica (FUNDECOL) en el manejo comunitario y participativo del ecosistema de manglar del cantón Muisne, provincia de Esmeraldas. In: Metodologías para facilitar procesos de gestión de los recursos naturales (M. B. Cevallos, M. Fajardo Yépez, M. Torres Benavides \& V. H. Torres Dávila, eds.): 133-172; Quito: CAMAREN-IEE. 
Los Pueblos Ancestrales del Ecosistema Manglar y su política de producción de comunes

GARY, J., 2000 - The political ecology of biodiversity. Biodiversity conservation and rural development at the indigenous and peasant grassroots, 257 pp.; Oxford: University of Oxford, Department of Philosophy. Tesis de doctorado.

GOBIERNO DEL ECUADOR, 1978 - Decreto Supremo 2939. Registro Oficial 596, 23 de octubre de 1978.

GOBIERNO DEL ECUADOR, 1989 - Decreto Ejecutivo 375. Registro Oficial 117, 26 de julio de 1989.

GOBIERNO DEL ECUADOR, 1995 - Decreto Ejecutivo 3327. Registro Oficial 848, 1 de junio de 1995.

GOBIERNO DEL ECUADOR, 1999 - Decreto Ejecutivo 11022. Registro Oficial 243, 21 de julio de 1999.

GOBIERNO DEL ECUADOR, 2008 - Constitución Política de la República del Ecuador. Registro Oficial No. 449, octubre, 2008.

GONZÁLEZ ANDRICAÍN, C., 2009 - Identidades étnicas en acción. La organización comunal de la península de Santa Elena ante la cooperación al desarrollo, 205 pp.; Quito: Ediciones Abya-Yala, Escuela Superior Politécnica del Litoral (ESPOL).

HAMILTON, J. \& PLACAS, A. J., 2011 - Anthropology Becoming...? The 2010 Sociocultural Anthropology Year in Review. American Anthropologist, 113 (2): 246-261.

HARVEY, D., 2005 - Spaces of Neoliberalization: Towards a Theory of Uneven Geographical Development, 132 pp.; Múnich: Franz Steiner Verlag.

HOFFMAN FRENCH, J., 2004 - Mestizaje and Law Making in Indigenous Identity Formation in Northeastern Brazil: "After the Conflict Came the History". American Anthropologist, 106 (4): 663-674.

HOOKER, J., 2005 - Indigenous Inclusion/Black Exclusion: Race, Ethnicity and Multicultural Citizenship in Latin America. Journal of Latin American Studies, 37 (2): 285-310.

LATORRE, S., 2013 - The politics of identification in a shrimp conflict in Ecuador: the political subject "Pueblos Ancestrales del Ecosistema Manglar" (Ancestral People of Mangrove Ecosystem). Journal of Latin American and Caribbean Anthropology, 18 (1): 67-89. doi:10.1111/jlca.12003.

LATORRE, S., FARRELL, K. N. \& MARTÍNEZ-ALIER, J., 2015 - The commodification of nature and socio-environmental resistance in Ecuador: An inventory of accumulation by dispossession cases, 1980-2013. Ecological Economics, 116: 58-69. doi:10.1016/j. ecolecon.2015.04.016.

LI, T., 2010 - Indigeneity, Capitalism, and the Management of Dispossession. Current Anthropology, 51 (3): 385-414.

MARCOS, J. G., 2005 - Los pueblos navegantes del Ecuador prehispánico, 206 pp.; Quito: Ediciones Abya-Yala, Escuela Superior Politécnica del Litoral (ESPOL).

MARRIOT GARCÍA, F., 2003 - Análisis del sector camaronero. Apuntes de Economía, N. ${ }^{\circ}$ 29, 60 pp.; Disponible en http://www.bce.fin.ec/docs.php?path=./documentos/ PublicacionesNota/Catalogo/Apuntes/ae29.pdf (consulta realizada el 15 de marzo de 2009).

MATTHEWS, G. V. T., 1993 - The Ramsar Convention on Wetlands: its History and Development, 87 pp.; Gland: Ramsar. Convention Bureau. Disponible en http:// www.ramsar.org/cda/en/ramsar-pubs-books-ramsar-convention-on21313/main/ ramsar/1-30-101\%5E21313_4000_0) (consulta realizada el 10 de abril de 2009).

NIEZEN, R., 2003 - The Origins of Indigenism: Human Rights and the Politics of Identity, xix +272 pp.; Berkley: University of California Press. 
OCHOA, E., 1995 - The Special Area Management Process. In: Eight years in Ecuador: the Road to Integrated Coastal Management (D. Robadue Jr., ed.): 144-170; Narragansett: Coastal Resources Center, University of Rhode Island.

OLSEN, S. B. \& COELLO, S., 1995 - Managing Shrimp Mariculture Development. In: Eight years in Ecuador: the Road to Integrated Coastal Management (D. Robadue Jr., ed.): 73-92; Narragansett: Coastal Resources Center, University of Rhode Island.

OLSEN, S., ROBADUE Jr., D. \& ARRIAGA, L., 1995 - A Brief Overview of Ecuador's Coastal Management Program. In: Eight years in Ecuador: the Road to Integrated Coastal Management (D. Robadue Jr., ed.): 8-45; Narragansett: Coastal Resources Center, University of Rhode Island.

PÉREZ, E. \& ROBADUE Jr., D., 1989 - Institutional Issues of Shrimp Mariculture in Ecuador. In: A sustainable shrimp mariculture industry in Ecuador (S. Olsen \& L. Arriaga, eds.): 71-88; Narragansett: Coastal Resources Center, University of Rhode Island.

ROBADUE Jr., D., 1995 - Eight years in Ecuador: the Road to Integrated Coastal Management, 319 pp.; Narragansett: Coastal Resources Center, University of Rhode Island.

SCHLOSBERG, D., 2004 - Reconceiving Environmental Justice: Global Movements and Political Theories. Environmental Politics, 13 (3): 517-540.

SUTINEN, J., BROADUS, J. \& SPURRIER, W., 1989 - Socio-economic aspects of shrimp mariculture. In: Establishing a sustainable shrimp mariculture industry in Ecuador (S. Olsen \& L. Arriaga, eds.): 19-44; Narragansett: Coastal Resources Center, University of Rhode Island.

TORRES, M. \& YÉPEZ, V., 1999 - Las comunidades de usuarios ancestrales del ecosistema de manglar y la industria camaronera: la comunicación y la educación como alternativas para el desarrollo local, 261 pp.; Quito: Pontificia Universidad Católica del Ecuador. Tesis de maestría.

WADE, P., 2010 [1997] - Race and ethnicity in Latin America, viii + 215 pp.; Londres, Nueva York: Pluto Press. 